\title{
New mesogenic compounds possessing a biphenyl ester and ether moiety comprising 1,3-dimethylbarbituric acid: synthesis, characterisation and mesomorphic studies
}

\author{
AbdulKarim-Talaq Mohammad, H. T Srinivasa, Hariprasad Suresh \& Guan- \\ Yeow Yeap
}

To cite this article: AbdulKarim-Talaq Mohammad, H. T Srinivasa, Hariprasad Suresh \& GuanYeow Yeap (2016) New mesogenic compounds possessing a biphenyl ester and ether moiety comprising 1,3-dimethylbarbituric acid: synthesis, characterisation and mesomorphic studies, Liquid Crystals, 43:9, 1174-1183, DOI: 10.1080/02678292.2016.1162857

To link to this article: http://dx.doi.org/10.1080/02678292.2016.1162857

View supplementary material $\widetilde{ }$

Published online: 31 Mar 2016.

Submit your article to this journal $₫$

Џ Article views: 121

Q View related articles $₫$

View Crossmark data $\nearrow$ 


\title{
New mesogenic compounds possessing a biphenyl ester and ether moiety comprising 1,3-dimethylbarbituric acid: synthesis, characterisation and mesomorphic studies
}

\author{
AbdulKarim-Talaq Mohammad ${ }^{a}$, H. T Srinivasa ${ }^{b}$, Hariprasad Suresh $\mathbb{C}^{c}$ and Guan-Yeow Yeap ${ }^{d}$ \\ ${ }^{a}$ Chemistry Department, College of Science, University of Anbar, Ramadi, Iraq; ${ }^{\text {b} R a m a n ~ R e s e a r c h ~ I n s t i t u t e, ~ S o f t ~ C o n d e n s e d ~ M a t t e r ~ G r o u p, ~}$ \\ Bengaluru, India; 'Department of Chemistry, Central College Campus, Bangalore University, Bengaluru, India; dLiquid Crystal Research \\ Laboratory, School of Chemical Sciences, Universiti Sains, Malaysia, Penang, Malaysia
}

\begin{abstract}
New substituted derivatives of 5-vinyl-1,3-dimethylbarbituric acid were synthesised and evaluated for liquid crystal properties. Two sets of molecules were prepared. One end of all the molecules possesses the 1,3-dimethylbarbituric core. The first set comprises biphenyl ethers, $\mathbf{4 a - n}$ and the second set biphenyl esters, 5a-g. Liquid crystalline properties were investigated by POM and DSC techniques. All the compounds exhibited enantiotropic smectic $A$ and nematic mesophases. The LC properties were found to depend on the spacer and terminal alkoxy- chain and alkoxy- ester moiety of the molecules. Smaller alkyl chain members showed a smectic phase, while higher alkyl chain members showed a nematic phase.
\end{abstract}

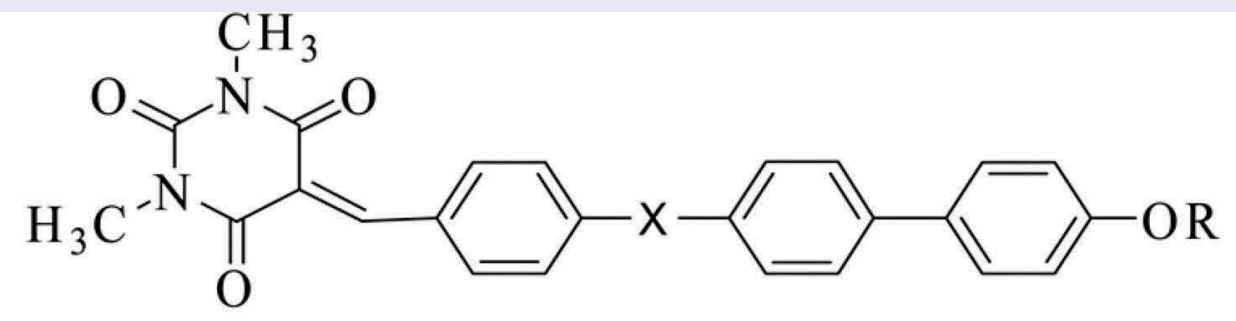

$$
\begin{aligned}
& \text { 4a-n. } X=\text { methylene, } R=\text { alkyl } \\
& \text { 5a-g. } X=\text { ester }, \quad R=-C O-\text { alkyl }
\end{aligned}
$$
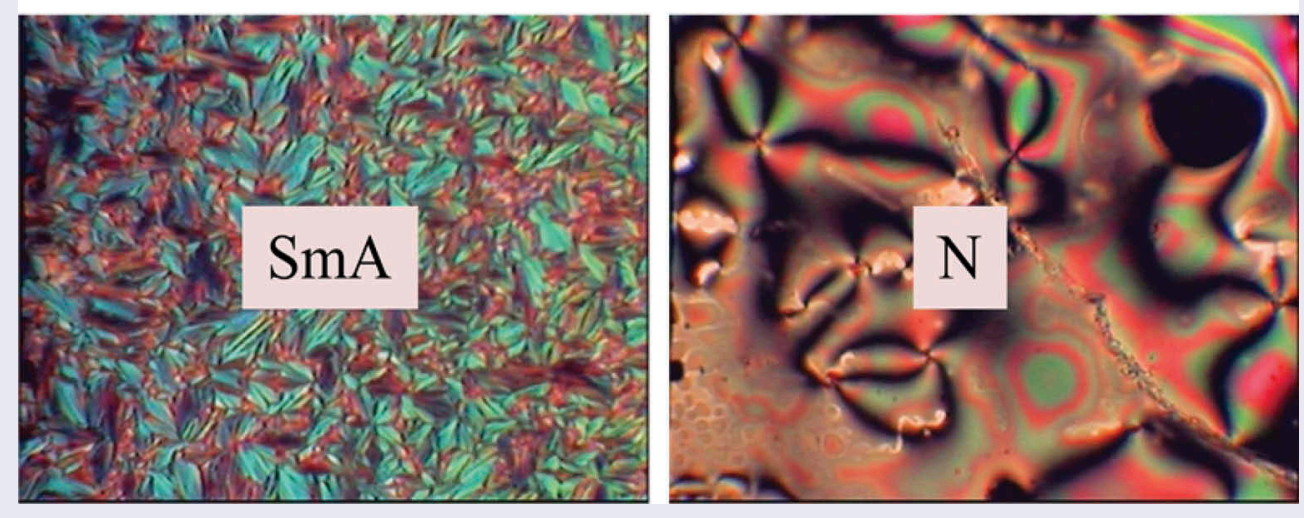

\section{ARTICLE HISTORY}

Received 6 December 2015

Accepted 3 March 2016

\section{KEYWORDS}

Liquid crystals; dimethyl barbiturates; dimers; mesophases; heterocycles

\section{Introduction}

Liquid crystal dimers are defined as a class of liquid crystals in which either two symmetric or non-symmetric mesogenic units are interlinked by a central flexible spacer.[1] Flexible fragments within the molecule play an important role in controlling the molecular shape and thus the transitional properties, with liquid crystal dimers acting as the most prominent 
example.[2-4] Dimers have recently attracted considerable attention from researchers due to occurrence of a twist-bend nematic phase, which has a very small and positive dielectric anisotropy and can be switched from an approximately planar to a homeotropic texture by relatively large electric fields.[5-7] A variety of new dimers have been prepared using conventional synthetic strategies utilising various structural parameters in connection with the dependence of phase transitional properties on the length and parity of the connecting spacer.[8-15] Moreover, symmetric and nonsymmetric liquid crystal dimers are characterised by exhibiting the unique optically uniaxial and biaxial smectic phases and intercalated smectic phases.[16,17] In addition, in the mesophase, the presence of a heterocyclic ring in either of the two mesogenic groups within dimers can induce a different kind of intermolecular interaction, and hence it would be useful if further studies can focus on this subject.[18] Previous studies have shown that hetero-atoms in the heterocyclic rings may cause changes in a variety of parameters such as dielectric anisotropy.[19] Most of the known oligomeric liquid crystals incorporate one or more five-member heterocyclic rings and many of these compounds exhibit smectogenic and nematogenic properties.[20,21] In this regard, barbituric acid itself has no end alkyl group but possesses a strong dipolar effect.

In continuation of our ongoing research on the synthesis of heterocycles containing liquid crystalline materials,[22-25] and for better understanding of the structure-liquid crystalline property relationship, we now report a study on the synthesis and characterisation of new mesogenic compounds containing barbituric acid moieties connected to a homologous ether terminal with a hexamethylene/octamethylene spacer and terminal ester groups. Elemental analysis, Fourier transform infrared (FT-IR), ${ }^{1} \mathrm{H}$ NMR and ${ }^{13} \mathrm{C}$ NMR spectroscopic studies support the proposed structure, while the mesomorphic properties of the title compounds were studied specifically using a polarising optical microscope (POM) and differential scanning calorimetry (DSC).

\section{Experimental}

\subsection{Materials}

Bromoalkanes, $\alpha, \omega$-dibromoalkanes, 4-hydroxybenzaldehyde, 1,3-dimethylbarbituric acid and 4,4'-dihydroxybiphenyl were purchased from Sigma-Aldrich. Thin layer chromatography analyses were performed using aluminium-backed silica gel plates (Merck 60 F254), with examination under UV light. Column chromatography was performed under the gravity method using Merck 60 mesh silica gel with a 1:1 ratio of ethyl acetate and petroleum ether as eluent.

\subsection{Instruments and measurements}

Microanalyses for all compounds were carried out using a Perkin Elmer 2400 LS series CHNS/O analyser. The IR spectra were recorded on a Perkin Elmer 2000 FT-IR spectrophotometer at a frequency range of $4000-400 \mathrm{~cm}^{-1}$ in which samples were embedded in $\mathrm{KBr}$ discs. NMR data were obtained using a Bruker 300 and $400 \mathrm{MHz}$ ultrashield spectrometer equipped with a $5 \mathrm{~mm}$ broadband inverse (BBI) gradient probe. A standard Bruker pulse programme[26] was used throughout the experiment. Complete ${ }^{1} \mathrm{H}$ NMR and ${ }^{13} \mathrm{C}$ NMR assignment of representative compounds was obtained and substantiated by means of ${ }^{1} \mathrm{H}-{ }^{1} \mathrm{H}$ correlation spectroscopy (COSY), ${ }^{13} \mathrm{C}-{ }^{1} \mathrm{H}$ heteronuclear multiple quantum correlation $\mathrm{HMQC}$ ) and ${ }^{13} \mathrm{C}-{ }^{1} \mathrm{H}$ heteronuclear multiple bond correlation (HMBC) spectroscopic measurements. Deuterated dimethylsulphoxide (DMSO- $\mathrm{d}_{6}$ ) was used as solvent, with TMS as the internal standard. Mesophase observation of texture was carried out with a Carl Zeiss Axioskop 40 optical microscope equipped with a Linkam LTS350 hot stage and TMS94 temperature controller. The phase-transition temperatures and associated enthalpy values were recorded using a differential scanning calorimeter (Elmer Pyris 1 DSC) operated at a scanning rate of $\pm 5^{\circ} \mathrm{C} \mathrm{min}{ }^{-1}$ for heating and cooling.

\subsection{Synthesis}

Synthesis of compounds $\mathbf{1 a}-\mathbf{b}, \mathbf{2} \mathbf{a}-\mathbf{g}$ and $\mathbf{3 a}-\mathbf{n}$ and target compounds 4a-n was carried out using the experimental procedure illustrated in Scheme 1. Compounds 1a-b were prepared by condensation reaction of 4-hydroxybenzaldehyde with 1,6-dibromohexane and 1,8-dibromooctane as reported previously. [22,23] Compounds 2a-g resulted from Williamson's etherification between 4,4'-dihydroxybiphenyl and bromoalkanes ranging from $\mathrm{C}_{6} \mathrm{H}_{13} \mathrm{Br}$ to $\mathrm{C}_{18} \mathrm{H}_{37} \mathrm{Br}$. Freshly prepared compounds $\mathbf{2 a - g}$ were subsequently reacted with compounds 1a-b by Williamson's method to yield the desired compounds, 3a-n. The condensation reaction between $\mathbf{3 a}-\mathbf{n}$ and 1,3-dimethylbarbituric acid resulted in compounds $\mathbf{4 a - n}$.

The target compounds $\mathbf{5 a - g}$ and their intermediates 2a-g, 3a-g and 4a-g were prepared according to Scheme 2. All target compounds were prepared by condensation of 4-formylphenyl $\quad 4^{\prime}$-(alkyloxy) 



Scheme 1. Synthesis of 1,3-dimethylbarbituric acid derivatives $4 a-n$ with ether terminus.

biphenyl-4'-carboxylate with 1,3-dimethylbarbituric acid in ethanol for $3 \mathrm{~h}$ according to a previously described method.[24,25]

\subsubsection{General synthetic procedure of title compounds $4 a-n$}

Compounds $\mathbf{4 a}-\mathbf{n}$ were synthesised according to a method described in the literature.[24,25,27,28] A mixture of 1,3-dimethylbarbituric acid $(128 \mathrm{mg}$, $0.827 \mathrm{mmol}$ ) and $3 \mathrm{a}(500 \mathrm{mg}, 0.827 \mathrm{mmol})$ was refluxed in absolute ethanol for $3 \mathrm{~h}$. Product $4 \mathrm{a}$, obtained as a precipitate from the hot reaction mixture, was repeatedly washed with hot ethanol and dried in vacuum to obtain a pure compound. The same procedure was applied to all other target compounds. The analytical data of FT-IR, ${ }^{1} \mathrm{H}$ NMR and ${ }^{13} \mathrm{C}$ NMR and elemental analysis are summarised below for the newly synthesised compounds (see Supplemental data):

(4a) 5-(6-(4'-(Hexyloxy)-biphenyl]-4-yloxy)hexyloxy)benzylidene)-1,3-dimethylpyrimidine-2,4,6

(1H,3H,5H)-trione: Yield 71\%. Analysis found for: $\mathrm{C}_{37} \mathrm{H}_{44} \mathrm{~N}_{2} \mathrm{O}_{6}(\%): \mathrm{C}, 72.30 ; \mathrm{H}, 7.42 ; \mathrm{N}, 4.65$. Calc C, 72.52; H, 7.24; N, 4.57; IR: $v_{\max }\left(\mathrm{KBr}, \mathrm{cm}^{-1}\right): 2989$, 2871, 1776, 1570, 1250; ${ }^{1} \mathrm{H}$ NMR $\delta$ (ppm, DMSO): $8.60(\mathrm{~s}, 1 \mathrm{H}), 6.97-8.83\left(\mathrm{~m}, 12 \mathrm{H}, \mathrm{C}_{6} \mathrm{H}_{5}\right), 4.17(\mathrm{t}, 2 \mathrm{H}$, $J=6.21 \mathrm{~Hz}), 4.09(\mathrm{t}, 2 \mathrm{H}, J=6.43 \mathrm{~Hz}), 3.96(\mathrm{t}, 2 \mathrm{H}$, $J=6.85 \mathrm{~Hz}), 3.42(\mathrm{~s}, 3 \mathrm{H}), 3.24(\mathrm{~s}, 3 \mathrm{H}), 0.79(\mathrm{t}, 3 \mathrm{H}) ;{ }^{13} \mathrm{C}$ NMR $\delta$ (ppm): 177.40, 169.03, $166.12(\mathrm{C}=\mathrm{O}), 162.89$ (Ar-C-O), $160.89(\mathrm{C}=\mathrm{C}), 114.22-140.97$ (Ar-C), 62.30 (C-O-C), $21.30\left(\mathrm{CH}_{2}\right), 14.50\left(\mathrm{CH}_{3}\right)$. (4k) 5-(8-(4'-(Dodecyloxy)-biphenyl]-4-yloxy)hexyloxy)benzylidene)-1,3-dimethylpyrimidine-2,4,6

(1H,3H,5H)-trione: Yield 70\%. Analysis found for: $\mathrm{C}_{45} \mathrm{H}_{60} \mathrm{~N}_{2} \mathrm{O}_{6}$ (\%): C, 74.30; H, 8.49; N, 3.69. Calc C, 74.55; H, 8.34; N, 3.86; IR: $v_{\max }\left(\mathrm{KBr}, \mathrm{cm}^{-1}\right): 2989$, 2862, 1775, 1584, 1254; ${ }^{1} \mathrm{H}$ NMR $\delta$ (ppm, DMSO): $8.60(\mathrm{~s}, 1 \mathrm{H}), 6.95-8.85\left(\mathrm{~m}, 12 \mathrm{H}, \mathrm{C}_{6} \mathrm{H}_{5}\right), 4.13(\mathrm{t}, 2 \mathrm{H}$, $J=6.75 \mathrm{~Hz}), 4.00(\mathrm{t}, 2 \mathrm{H}, J=6.12 \mathrm{~Hz}), 3.91(\mathrm{t}, 2 \mathrm{H}$, $J=6.84 \mathrm{~Hz}), 3.44(\mathrm{~s}, 3 \mathrm{H}), 3.25(\mathrm{~s}, 3 \mathrm{H}), 0.84(\mathrm{t}, 3 \mathrm{H}) ;{ }^{13} \mathrm{C}$ NMR $\delta(\mathrm{ppm}): 176.00,168.11,165.38(\mathrm{C}=\mathrm{O}), 163.32$ (Ar-C-O), $161.85(\mathrm{C}=\mathrm{C}), 115.44-140.07(\mathrm{Ar}-\mathrm{C}), 62.20$ (C-O-C), $22.90\left(\mathrm{CH}_{2}\right), 15.25\left(\mathrm{CH}_{3}\right)$.

(5g) 4-((1,3-Dimethyl-2,4,6-trioxotetrahydropyrimidin-5(2H)-ylidene)methyl)phenyl 4'-(octadecanoyloxy)-[1,1'-biphenyl]-4-carboxylate: Yield 71\%. Analysis found for $\mathrm{C}_{44} \mathrm{H}_{54} \mathrm{~N}_{2} \mathrm{O}_{7}(\%)$ : C, 73.25; $\mathrm{H}$, 7.60; N, 3.96. Calc C, 73.10; H, 7.53; N, 3.88; IR: $\boldsymbol{v}_{\max }$ $\left(\mathrm{KBr}, \mathrm{cm}^{-1}\right): 2980,2879,1751,1597,1544 ;{ }^{1} \mathrm{H}$ NMR $\delta$ (ppm, DMSO): $8.48(\mathrm{~s}, 1 \mathrm{H}), 6.84-8.60\left(\mathrm{~m}, 12 \mathrm{H}, \mathrm{C}_{6} \mathrm{H}_{5}\right)$, $3.21(\mathrm{~s}, 3 \mathrm{H}), 3.16(\mathrm{~s}, 3 \mathrm{H}), 2.21(\mathrm{t}, 2 \mathrm{H}, J=6.78 \mathrm{~Hz}), 0.98$ $(\mathrm{t}, 3 \mathrm{H}) .{ }^{13} \mathrm{C}$ NMR $\delta(\mathrm{ppm}): 172.45,168.12,163.08$ $(\mathrm{C}=\mathrm{O}), 161.90(\mathrm{C}=\mathrm{C}), 115.05-141.98(\mathrm{Ar}-\mathrm{C}), 22.20$ $\left(\mathrm{CH}_{2}\right), 15.24\left(\mathrm{CH}_{3}\right)$.

\section{Results and discussion}

\subsection{Chemical structure characterisation}

From the FT-IR spectra it was observed that diagnostic bands of the alkyl groups were present in the frequency range $2993-2860 \mathrm{~cm}^{-1}$. The relative intensity of these 
bands increased on ascending the series due to the increase in carbon number of the alkyl groups at both terminals.[27] The bands appearing within the frequency range $1776-1768 \mathrm{~cm}^{-1}$ can be ascribed to the stretching of $\mathrm{C}=\mathrm{O}$ carbonyl.[22] An additional band, attributed to stretching of the ether linkage $\mathrm{C}-\mathrm{O}$, is observed in the range $1254-1250 \mathrm{~cm}^{-1}$.

Complete ${ }^{1} \mathrm{H}$ NMR and ${ }^{13} \mathrm{C}$ NMR, DEPT 135 assignment, along with 2D COSY, HMQC and HMBC, was obtained for the title compounds $4 \mathbf{a}-\mathbf{n}$. Based on representative compound $\mathbf{4 h}$, a complete assignment for the title compounds is described. The ${ }^{1} \mathrm{H}$ NMR spectrum of compound $4 \mathrm{~h}$ indicated a singlet, which is attributed to $(\mathrm{Ph}-\mathrm{CH}=)$, at $8.63 \mathrm{ppm}$. This substantiates the finding of a reaction between 1,3-dimethylbarbituric acid and 3h. The absorption of 12 aromatic protons from two different distinguishable positions at the rings gave rise to a multiplet between 6.97 and $8.63 \mathrm{ppm}$. The same ${ }^{1} \mathrm{H}$ NMR spectra also show the resonance resulting from aliphatic protons. These signals are assigned using the COSY experiment. Three overlapping triplets, attributed to the ethoxy protons $\left(\mathrm{O}-\mathrm{CH}_{2}\right)$ of the spacer and ether terminal groups, are evident at slightly higher fields within the frequencies $4.20,4.06$ and $3.98 \mathrm{ppm}$. The fact that two overlapping triplets are observed instead of one suggests that the molecule is non-symmetric. Two singlets observed at 3.42 and $3.24 \mathrm{ppm}$ were assigned to a methyl group attached to $\mathrm{N}$ atoms in 1,3-dimethylbarbituric acid. Moreover, in the ${ }^{1} \mathrm{H}$ NMR spectrum of compound $4 \mathrm{~h}$, a triplet was observed at the high field of $0.85 \mathrm{ppm}$, which can be assigned to the methyl protons of the terminal alkyl groups.

Complete ${ }^{1} \mathrm{H}$ NMR and ${ }^{13} \mathrm{C}$ NMR, DEPT 135 assignment, along with 2D COSY, HMQC and HMBC, was applied to title compounds $\mathbf{5 a - g}$. Based on representative compound $\mathbf{5 a}$, a complete assignment for the title compounds can be described. The ${ }^{1} \mathrm{H}$ NMR spectrum of compound $\mathbf{5 a}$ indicated a singlet, which is attributed to $(\mathrm{Ph}-\mathrm{CH}=)$, at $8.43 \mathrm{ppm}$. This substantiates the occurrences of a reaction between 1,3dimethylbarbituric acid and the other part of biphenyl. The absorption of 12 aromatic protons from two different distinguishable positions at the rings gave rise to a multiplet between 6.98 and $8.62 \mathrm{ppm}$. The same ${ }^{1} \mathrm{H}$ NMR spectra also show the resonance resulting from aliphatic protons. These signals are assigned by the COSY experiment. In the ${ }^{1} \mathrm{H}$ NMR spectrum of compound 5a, a triplet was observed at the high field at $0.88 \mathrm{ppm}$, which can be assigned to the methyl protons of the terminal alkyl chains.

The ${ }^{13} \mathrm{C}$ NMR spectra of compound $\mathbf{5 a}$ indicate that the diagnostic peaks observed within the range $\delta=171.89-162.89 \mathrm{ppm}$ can be attributed to the presence of carbonyl groups $(\mathrm{C}=\mathrm{O})$. The peak at $\delta=160.67 \mathrm{ppm}$ is due to the carbonyl carbons of $1,3-$ dimethylbarbituric acid. The aromatic carbons give signals in the range $\delta=122.11-150.20 \mathrm{ppm}$. The signal at 118.2 and $148.2 \mathrm{ppm}$ can be assigned as vinyl carbons $(\mathrm{C}=\mathrm{C})$ attached to 1,3-dimethylbarbituric acid. At a high field, a signal at $\delta=14.66 \mathrm{ppm}$ can be assigned to methyl carbons in the ester chain.

\subsection{Mesomorphic characterisation}

The mesomorphic properties of compounds 5-(6-(4'(hexyloxy)biphenyl-4-yloxy)hexyloxy)benzylidene)1,3-dimethylpyrimidine-2,4,6(1H,3H,5H)-trione $\mathbf{4 a}-\mathbf{n}$ and 4-((1,3-dimethyl-2,4,6-trioxotetrahydropyrimidin$5(2 \mathrm{H}$ )-ylidene)methyl)phenyl 4'-(alkyloxy)-[1,1'-biphenyl]-4-carboxylates $\mathbf{5 a - g}$ were studied in regard to their mesomorphic properies. The phase transitions and corresponding enthalpy changes of mesophases were determined for compounds $4 \mathbf{a}-\mathbf{n}$ and $\mathbf{5 a}-\mathbf{g}$ by a combination of DSC and POM. Solid samples were sandwiched between an untreated glass plate and cover slip and subjected to heating followed by cooling scans at a rate of $5{ }^{\circ} \mathrm{C} / \mathrm{min}$ for textural observation by POM. The phase-transition temperatures and corresponding enthalpy changes obtained on the first heating and cooling scans are tabulated in Tables 1 and 2 .

Table 1. Transition temperatures and enthalpies $\left(\Delta \mathrm{H} \mathrm{kJ} / \mathrm{mol}^{-1}\right)$ of compounds $4 \mathrm{a}-\mathrm{n}$ at heating/cooling scan rates of $5{ }^{\circ} \mathrm{C}$ min.

\begin{tabular}{|c|c|c|c|}
\hline Compound & $\mathrm{n}$ & $\mathrm{R}$ & Heating scan/Cooling scan $\left({ }^{\circ} \mathrm{C}\right)$ \\
\hline $4 a$ & 6 & $\mathrm{C}_{6} \mathrm{H}_{13}$ & $\begin{array}{l}\text { Cr } 137.2(30.28) \text { SmA } 154.7(1.12) \text { I } \\
\text { Cr } 132.9(19.60) \text { SmA } 149.2(-1.78)) \text { I }\end{array}$ \\
\hline $4 b$ & 6 & $\mathrm{C}_{8} \mathrm{H}_{17}$ & $\begin{array}{l}\text { Cr } 146.8(22.18) \text { SmA } 158.8(2.44) \text { I } \\
\text { Cr } 135.7(-18.79) \text { SmA } 150.3(-2.96) \text { I }\end{array}$ \\
\hline $4 c$ & 6 & $\mathrm{C}_{10} \mathrm{H}_{21}$ & $\begin{array}{l}\text { Cr } 151 \text { (14.56) SmA } 168.1 \text { (3.88) I } \\
\text { Cr 147.6 (-31.42) SmA } 164.9(-3.47) \text { I }\end{array}$ \\
\hline $4 d$ & 6 & $\mathrm{C}_{12} \mathrm{H}_{25}$ & $\begin{array}{l}\text { Cr } 157.9(28.67) \text { N } 173.4(4.05) \text { I } \\
\text { Cr } 150.3(-19.00) \text { N } 168.2(-4.21) \text { I }\end{array}$ \\
\hline $4 e$ & 6 & $\mathrm{C}_{14} \mathrm{H}_{25}$ & $\begin{array}{l}\text { Cr } 160.9(23.57) \text { N } 180 \text { (6.64) I } \\
\text { Cr } 156.7(-17.50) \text { N } 175.3(-4.95) \text { I }\end{array}$ \\
\hline $4 f$ & 6 & $\mathrm{C}_{16} \mathrm{H}_{33}$ & $\begin{array}{l}\text { Cr } 165.1(16.77) \text { N } 184.5(6.98) \text { I } \\
\text { Cr } 161.2(-19.67) \text { N } 180(-5.18) \text { I }\end{array}$ \\
\hline $4 g$ & 6 & $\mathrm{C}_{18} \mathrm{H}_{37}$ & $\begin{array}{l}\text { Cr } 171.8(20.23) \text { N } 191.3(8.79) \text { I } \\
\text { Cr } 167.9(-26.15) \text { N } 186(-6.55) \text { I }\end{array}$ \\
\hline $4 \mathrm{~h}$ & 8 & $\mathrm{C}_{6} \mathrm{H}_{13}$ & $\begin{array}{l}\text { Cr } 140.1(19.10) \text { SmA } 158(0.98) \text { I } \\
\text { Cr } 135.2(26.76) \text { SmA } 152.3(-0.85)) \text { I }\end{array}$ \\
\hline $4 i$ & 8 & $\mathrm{C}_{8} \mathrm{H}_{17}$ & $\begin{array}{l}\text { Cr } 141.8(18.50) \text { SmA } 164.5(1.58) \text { I } \\
\text { Cr } 137.3(-21.31) \text { SmA } 159.3(-0.96) \text { I }\end{array}$ \\
\hline $4 j$ & 8 & $\mathrm{C}_{10} \mathrm{H}_{21}$ & $\begin{array}{l}\text { Cr } 154.1(26.17) \text { N } 176.2(1.97) \text { I } \\
\text { Cr } 150.8(-20.04) \text { N } 171.1(-1.60) \text { I }\end{array}$ \\
\hline $4 k$ & 8 & $\mathrm{C}_{12} \mathrm{H}_{25}$ & $\begin{array}{l}\text { Cr } 160.7(19.20) \text { N } 182.7(2.18) \text { I } \\
\text { Cr } 159.4(-27.04) \text { N } 177.7(-2.51) \text { I }\end{array}$ \\
\hline 41 & 8 & $\mathrm{C}_{14} \mathrm{H}_{29}$ & $\begin{array}{l}\text { Cr } 166.1(26.44) \text { N } 189.5(3.05) \text { I } \\
\text { Cr } 162(-19.97) \text { N } 182.7(-3.02) \text { I }\end{array}$ \\
\hline $4 m$ & 8 & $\mathrm{C}_{16} \mathrm{H}_{33}$ & $\begin{array}{l}\text { Cr } 175.6(23.92) \text { N } 194.2(4.44) \text { I } \\
\text { Cr } 171.1(-30.51) \text { N } 189.2(-3.84) \text { I }\end{array}$ \\
\hline $4 n$ & 8 & $\mathrm{C}_{18} \mathrm{H}_{37}$ & $\begin{array}{l}\text { Cr } 183.1(19.20) \text { N } 205.2(5.56) \text { I } \\
\text { Cr } 178.6(-24.08) \text { N } 199.9(-4.89) \text { I }\end{array}$ \\
\hline
\end{tabular}

$\mathrm{Cr}$, crystalline state, SmA, smectic A phase, $\mathrm{N}$, nematic phase, I, isotropic phase. 
Table 2. Transition temperatures and enthalpies $\left(\Delta \mathrm{H} \mathrm{kJ} / \mathrm{mol}^{-1}\right)$ of compounds $5 \mathrm{a}-\mathrm{g}$ at heating/cooling scan rates of $5{ }^{\circ} \mathrm{C} \mathrm{min}$.

\begin{tabular}{|c|c|c|}
\hline Compound & $\mathrm{n}$ & Heating scan/Cooling scan $\left({ }^{\circ} \mathrm{C}\right)$ \\
\hline $5 a$ & 6 & $\begin{array}{l}\text { Cr } 131(40.09) \text { I } \\
\text { Cr } 117.2(-29.43) \text { I }\end{array}$ \\
\hline $5 b$ & 8 & $\begin{array}{l}\text { Cr } 107.2(37.18) \text { SmA } 139.5(2.44) \text { I } \\
\text { Cr } 97.9(-19.09) \text { SmA } 128.8(-2.80) \text { I }\end{array}$ \\
\hline $5 c$ & 10 & $\begin{array}{l}\text { Cr } 118.3(40.58) \text { SmA } 146.3(4.03) \text { I } \\
\text { Cr } 110(-31.50) \text { SmA } 138.2(-3.79) \text { I }\end{array}$ \\
\hline $5 d$ & 12 & $\begin{array}{l}\text { Cr } 129.9 \text { (23.79) SmA } 154(5.23) \text { I } \\
\text { Cr } 122.1(-19.78) \text { SmA } 144.8(-5.50) ।\end{array}$ \\
\hline $5 e$ & 14 & $\begin{array}{l}\text { Cr } 142.1(30.80) \text { N } 162(6.79) \text { I } \\
\text { Cr } 128(-19.29) \text { N } 149.3(-7.68) \text { I }\end{array}$ \\
\hline $5 f$ & 16 & $\begin{array}{l}\text { Cr } 155(19) \mathrm{N} 169.2(8.93) \text { I } \\
\text { Cr } 138.1(-20.21) \mathrm{N} 160.1(-9.33) \text { I }\end{array}$ \\
\hline $5 \mathrm{~g}$ & 18 & $\begin{array}{l}\text { Cr } 175.5(29.79) \text { N } 189.2(7.34) \text { I } \\
\text { Cr } 130.8(-50.11) \text { N } 159.7(-8.44) \text { I }\end{array}$ \\
\hline
\end{tabular}

$\mathrm{Cr}$, crystalline phase, SmA, csectic A phase, $\mathrm{N}$, nematic phase, I, isotropic phase.

Compounds 4a-g had methylene spacer length $\mathrm{n}=6$ and terminal alkyl chain ranging from $\mathrm{n}=6-$ 18, whereas compounds $\mathbf{4 h}-\mathbf{n}$ has methylene spacer length $\mathrm{n}=8$ and terminal spacer alkyl chain ranging from $\mathrm{n}=6-18$. Molecules 4a-n tended to exhibit enantiotropic liquid crystal properties. In the first set of compounds, $4 \mathbf{a}-\mathbf{g}$, the SmA phase was observed in compounds 4a-c whereas compounds 4d-g showed the nematic phase. Representative DSC scans of $\mathbf{4 b}$ are shown in Figure 1. For example, compound $\mathbf{4 b}$ shows transitions at $146.08{ }^{\circ} \mathrm{C}(22.18)$ and $158.82{ }^{\circ} \mathrm{C}$ (2.44) on heating scans, which corresponds to the Cr-
SmA-Iso phase sequence. In the cooling scan, the converse transitions were abserved at $150.30{ }^{\circ} \mathrm{C}(-2.96)$ and $135.70{ }^{\circ} \mathrm{C}(-18.79)$, which corresponds to the IsoSmA-Cr phase. Compounds $\mathbf{4 d - g}$ show an enantiotropic nematic phase with schlieren texture. The difference in mesophase behaviour between $4 \mathbf{a}-\mathbf{c}$ and $\mathbf{4 d}-\mathbf{g}$ molecules can be explained by the number of aliphatic chains present at the periphery and the spacer position of the molecules. In this regard, a smaller aliphatic chain seems to be a coordinator in terms of achieving good packing, with less random orientation of the molecules possibly resulting in SmA mesophase. In the case of $\mathbf{4 d - g}$, the peripheral and spacer alkyl chains dis not allow molecules to pack with each other due to the bulky 1,3-dimethylbarbituric acid group, resulting in a nematic phase.

The second set of compounds, $\mathbf{4 h}-\mathbf{n}$, show similar characteristics to first set. Only two members, $\mathbf{4 h}$ and 4i, show an enantiotropic SmA phase whereas members $4 \mathbf{j}-\mathbf{n}$ show an enantiotropic nematic phase. The focal-conic textures of the SmA phase for $4 \mathbf{i}$ are shown in Figure 2(a) and 2(b). For instance, compound 4n was heated to its isotropic transition at $205.17^{\circ} \mathrm{C}$ (5.56) then cooled to $196^{\circ} \mathrm{C}$, and it displayed schlerien texture for the nematic phase as shown in Figure 2(c). This characteristic feature indicates that the alkylene spacer plays a role in the formation of mesophase. In general, in both sets of compounds, $4 \mathbf{a}-\mathbf{g}$ and $4 \mathbf{h}-\mathbf{n}$,
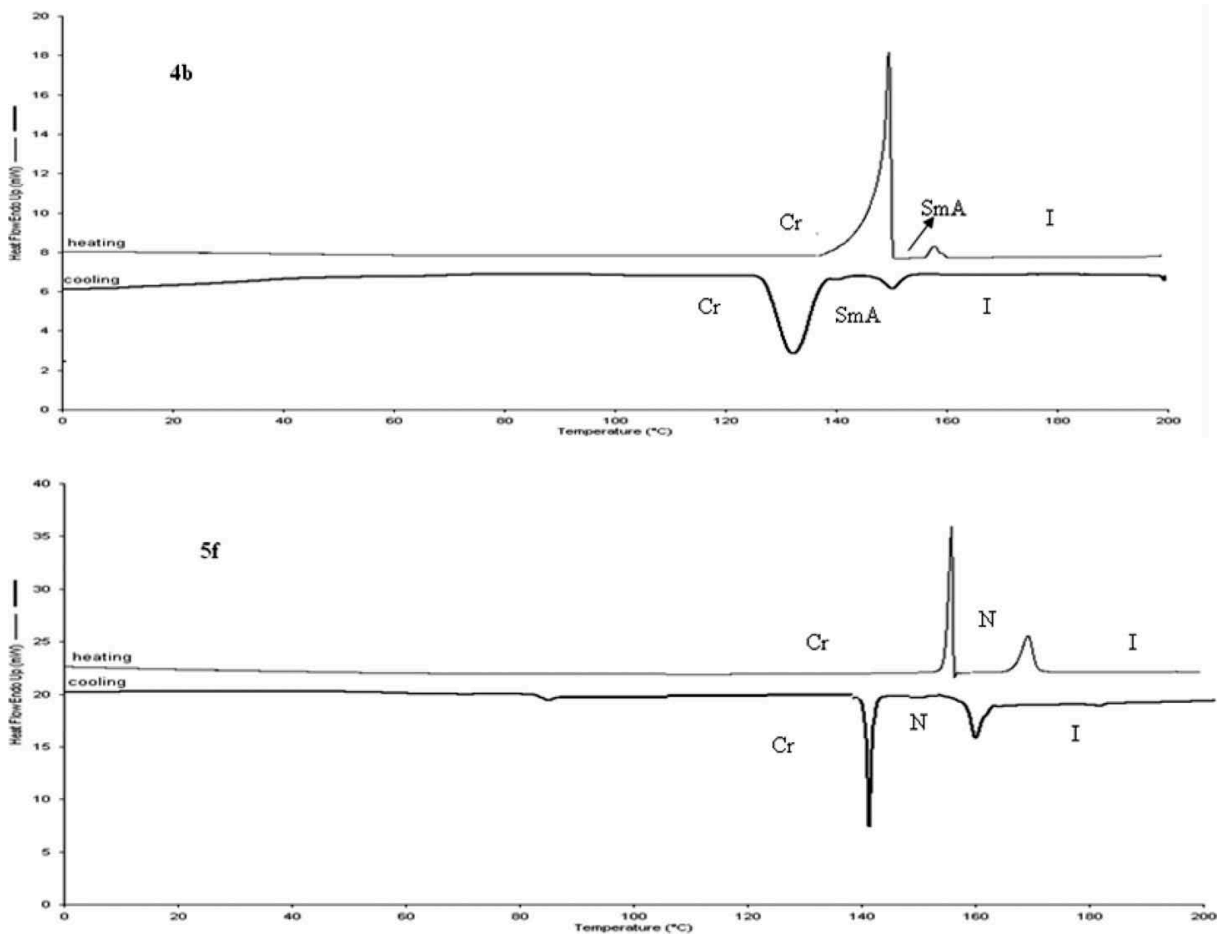

Figure 1. DSC scans of compounds $4 b$ and $5 f$. 


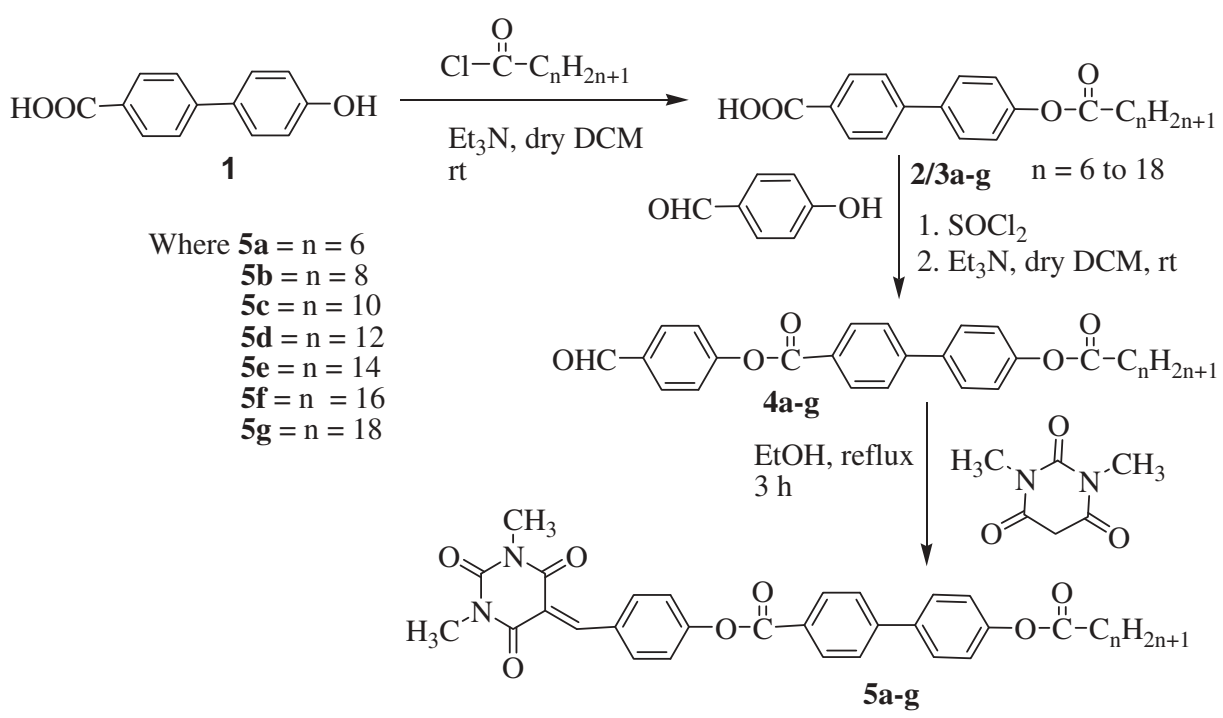

Scheme 2. Synthesis of 1,3-dimethylbarbituric acid derivatives $5 \mathrm{a}-\mathrm{g}$ with ester terminus.
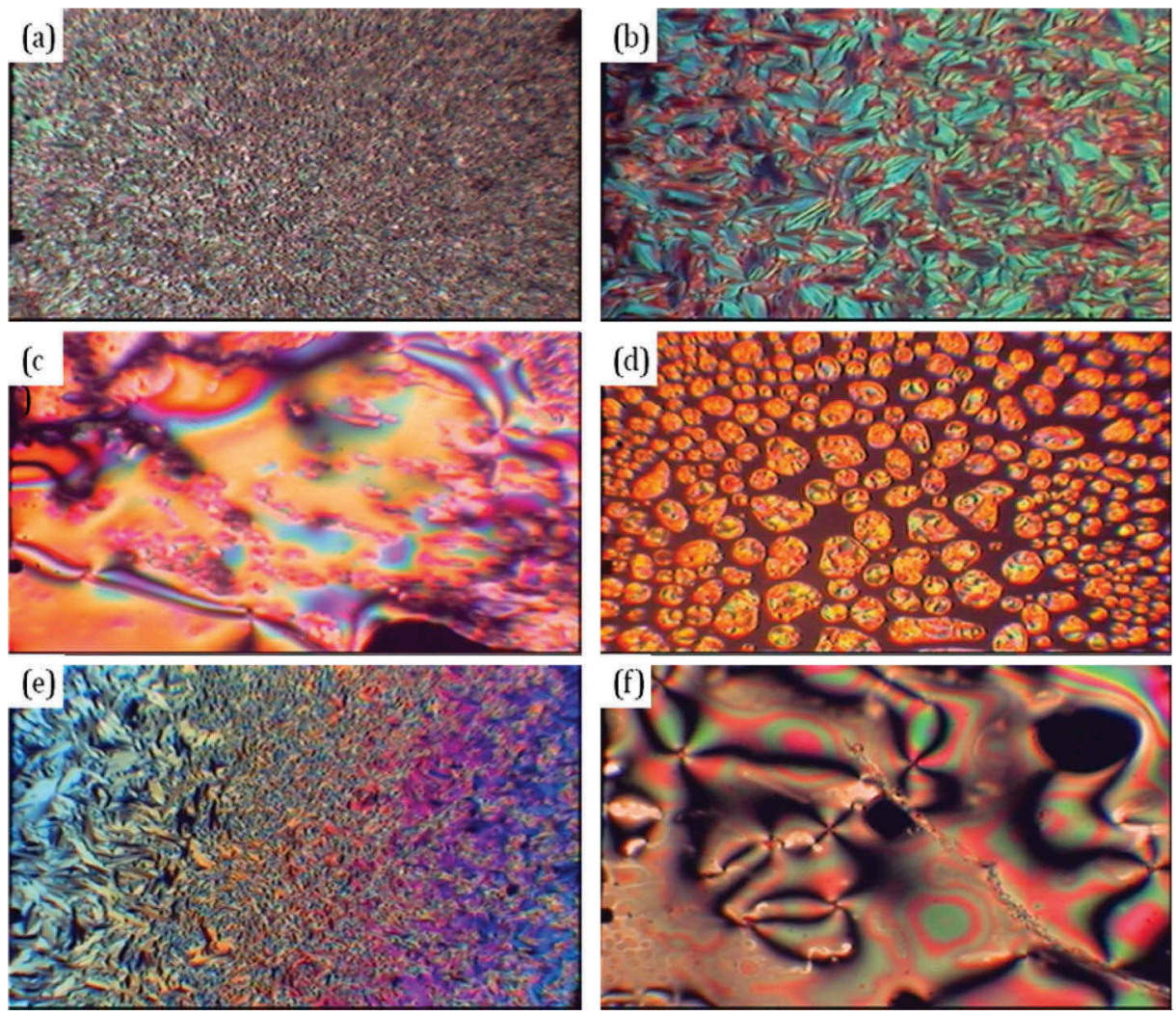

Figure 2. (colour online) (a) Optical photomicrograph of compound 4i exhibiting SmA upon cooling at early-stage $159^{\circ} \mathrm{C}$. (b) $4 \mathrm{i}$ upon cooling to completely grown stage displaying SmA at $144^{\circ} \mathrm{C}$. (c) 4 n displaying nematic phase upon cooling at $196{ }^{\circ} \mathrm{C}$. (d) $5 \mathrm{~d}$ exhibiting batonnet texture for $\mathrm{SmA}$ phase upon cooling at $143{ }^{\circ} \mathrm{C}$. (e) $5 \mathrm{c}$ displaying SmA phase at $128{ }^{\circ} \mathrm{C}$. (f) Compound $5 f$ displaying nematic phase at $162{ }^{\circ} \mathrm{C}$ in cooling scan.

lower members tend to exhibit the SmA phase and higher members tend to exhibit the nematic phase.

The phase-transition temperatures and corresponding enthalpy changes indicated that compound $\mathbf{5 a}$ was nonmesogenic. DSC measurement exhibited an endothermic peak at $131{ }^{\circ} \mathrm{C}$ (40.09) while there was an exothermic peak at $117.22^{\circ} \mathrm{C}(-29.43)$. These peaks were detected for phase-transition Cr-I upon heating, and I-Cr upon cooling. Compounds $\mathbf{5 b}-\mathbf{g}$ are mesogenic. Under POM and following heating, the batonnet texture of the SmA phase 
was produced by compounds $\mathbf{5 b}-\mathbf{d}$ - as shown in Figure $2(\mathrm{~d})$ for $\mathbf{5 d}$. In the case of $\mathbf{5} \mathbf{c}$, following cooling from the clearing point, the SmA phase emerged with typical focal-conic texture as shown in Figure 2(e). Interestingly, the enthalpies of isotropic transitions increase regularly with increase in carbons in the terminal alkoxy chains.

Compounds 5e-g exhibited a nematic phase following heating and cooling. DSC scans of compound $\mathbf{5} \mathbf{f}$ are shown in Figure 1. Following cooling, POM revealed the texture as having a schlieren nematic phase as shown in Figure 2 (f), and this texture was retained to crystallisation at 138.11 ${ }^{\circ} \mathrm{C}(-20.21)$.

Generally, in dimeric compounds, transition temperatures follow a pronounced add-even effect, meaning that an odd number of spacer molecules results in low melting transition temperatures while an even number results in high melting transition temperatures. This behaviour is most commonly attributed to the pronounced dependence on the molecular shape, length and parity of the spacer.[29] Such behaviour is alleged to occur because of the different shapes of the conformers with odd- or even-membered spacers and their associated conformational distribution.[30] In the present series of dimers, the add-even effect was eliminated and the values of the clearing entropies for the series $4 a-$ n, and particularly those showing SmA-I transitions, are very low. This is presumably due to the rather bulky shape of the barbituric acid group, and the resultant increased molecular biaxiality has been used to account for low clearing entropies. Thus, the orientational order is not enhanced and lower enthalpy values for SmA-I transitions would be expected.[31,32]

Figure 3(a), 3(b) and 3(c) shows the dependence of the cooling scan transition temperatures on the number of carbon atoms in the terminal alkoxy chains from $\mathrm{n}=6$ to 18 for compounds $4 \mathbf{a}-\mathbf{g}, 4 \mathbf{h}-\mathbf{n}$ and $5 \mathbf{b}-\mathbf{g}$, respectively. It is apparent that both melting points and isotropic temperatures show a gradually increasing tendency with increasing number of carbon atoms in the terminal alkyl chain. In the case of ester compounds $\mathbf{5 a -}$ g, the transition temperatures are reduced to almost $30-40{ }^{\circ} \mathrm{C}$ when compared to ether derivatives $4 \mathbf{a}-\mathbf{n}$. Interestingly, $\mathbf{5 g}$ with carbon atoms $\mathrm{n}=18$ in the terminal chain shows little decrease in Cr-Iso temperatures. This may be due to the increased random orientation of the molecule and lower van der Waals attractive forces between the terminal and spacer alkyl chains.

In comparison with the studies of compounds $4 \mathbf{a}-\mathbf{n}$ and $5 \mathbf{a}-\mathbf{g}$ revealed that both transition temperatures
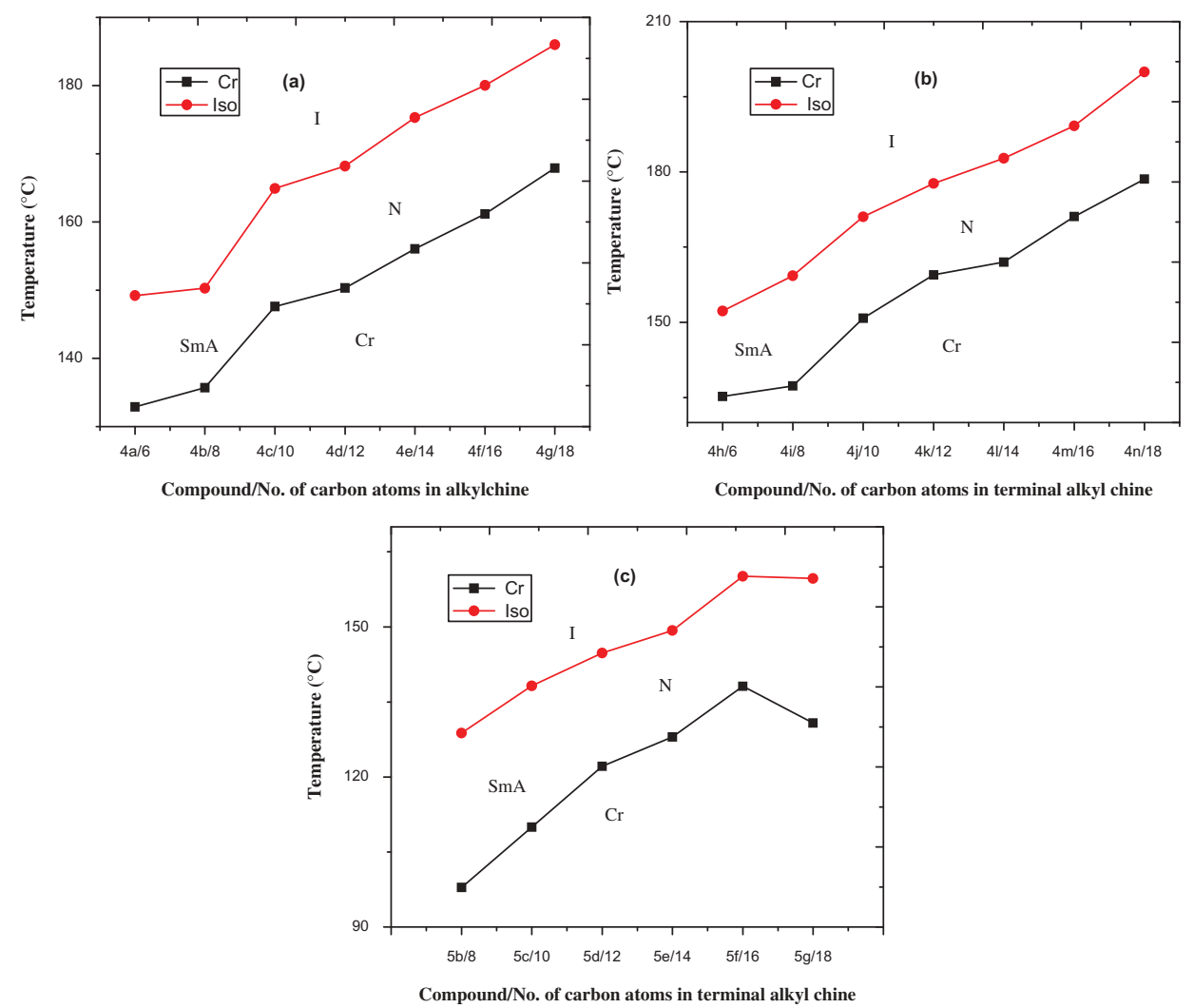

Figure 3. (colour online) Dependence of transition temperature as a function of number of carbon atoms in the terminal chain for the sets of compounds (a) $4 a-g$, (b) $4 h-n$ and (c) $5 b-g$. 
(a)

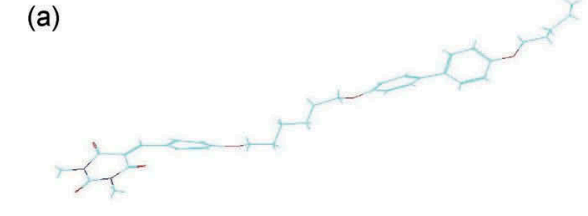

(h)



(g)

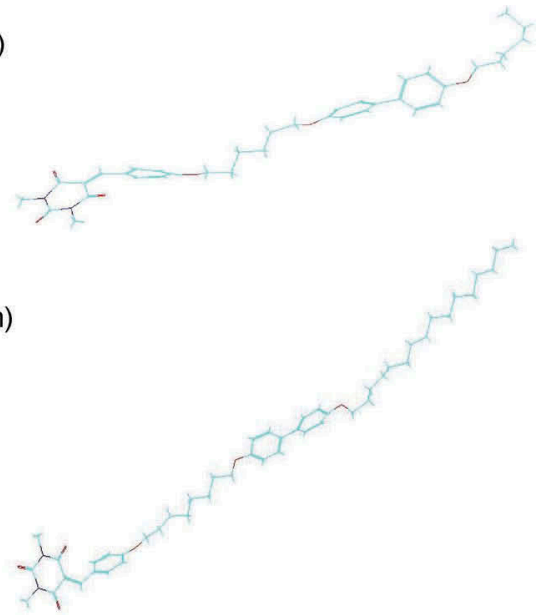

Figure 4. (colour online) Molecular models of compounds $4 \mathrm{a}, 4 \mathrm{~g}$, $4 \mathrm{~h}$ and $4 \mathrm{~m}$ using the HyperChem program.

and enthalpies increased along with the number of carbon atoms increased in the terminal alkyl chains. Lower members exhibit a SmA mesophase while higher members exhibit a nematic mesophase, and in both series the nematogenic properties of the compounds increased with increased terminal chain length. The phase behaviour shown by both series of compounds is unusual: the dimeric liquid crystals shows conventional smectogenic property when spacer chain length increases. Unusual nematic phase behavior is found in the longer spacer compounds.[33]

\subsection{Molecular model calculations}

Molecular model studies were carried out using the HyperChem programme to gain a better understanding of the relationship between the structure and type of phase of the molecules. Molecular models of compounds 4a, $4 \mathrm{~g}, \mathbf{4 h}$ and $\mathbf{4 m}$ are depicted in Figure 4, where the length of the methylene spacer varied from $n=6$ and 8 and where ever comes. The model data and experimental results are in agreement with the title compounds.

The molecular models show that in $\mathbf{4 a}$ and $\mathbf{4 g}$ the barbituric acid and the opposite-side extreme end of the phenyl ring of the molecule are in one plane, while the middle phenyl rings adjacent to the spacer are in another plane. The converse is the case for $\mathbf{4 h}$ and $\mathbf{4 m}$. The orientation of the middle phenyl rings depends on the number of carbon atoms in the alkoxy spacer. Overall non-planar molecule geometry appears rodlike and favours smectic and nematic mesophases. Variation in length at the terminal alkyl chain did not change the type of phase. Surprisingly, the type of phase is mainly dependent on the length of the spacer.

\section{Conclusions}

Two new sets of compounds derived from 1,3dimethylbarbituric acid connected to a biphenyl core via ether and an ester group were synthesised and characterised. All compounds presented enantiotropic LC properties with SmA and nematic mesophases. Transition temperatures were found to increase by increasing the number of carbon atoms in the terminal alkoxy chains for all non-symmetric compounds. Smaller alkyl chain members exhibited SmA phase while higher members exhibited nematic phase. It was observed that the connection of 1,3-dimethylbarbituric acid to the linear part of the other end of the compounds did not allow for good packing of the molecules, leading to nematic phase in higher members which is supported by theoretical calculations.

\section{Acknowledgements}

AK-T M extends grateful thanks to Prof. John West and Liquid Crystal Institute at Kent State University for performing theoretical calculations, and their hospitality.

\section{Disclosure statement}

No potential conflict of interest was reported by the authors.

\section{Funding}

The authors would like to thank the University of Anbar, Iraq and Universiti Sains Malaysia for supporting this project.

\section{ORCID}

HariPrasad Suresh (D) http://orcid.org/0000-0001-7157-1538 


\section{References}

[1] Imrie CT, Henderson PA. Liquid crystal dimers and higher oligomers: between monomers and polymers. Chem Soc Rev. 2007;36:2096-2124. DOI:10.1039/ b714102e.

[2] Abraham S, Mallia VA, Ratheesh KV, et al. Reversible thermal and photochemical switching of liquid crystalline phases and luminescence in diphenylbutadiene based mesogenic dimers. J Am Chem Soc. 2006;128:7692-7698. DOI:10.1021/ja06157k.

[3] Yelamaggad CV, Mathews M, Hiremath US, et al. Selfassembly of chiral mesoionic heterocycles into smectic phases: a new class of polar liquid crystal. Tetrahedron Lett. 2005;46:2623-2626. DOI:10.1016/j.tetlet.2005.02.084.

[4] Lee JW, Jin J-I, Achard MF, et al. Incommensurability induced by intermolecular hydrogen bonding. Liq Cryst. 2001;28:663-671. DOI:10.1080/02678290010028726.

[5] Henderson PA, Imrie CT. Methylene-linked liquid crystal dimers and the twist-bend nematic phase. Liq Cryst. 2011;38:1407-1414. DOI:10.1080/02678292.2011.624368.

[6] Borshch V, Kim YK, Xiang J, et al. Nematic twist-bend phase with nanoscale modulation of molecular orientation. Nature Commun. DOI:10.1038/ncomms3635.

[7] Cestari M, Diez-Berart S, Dunmur DA, et al. The phase behaviour and properties of the liquid crystal dimer $\alpha, \omega$ bis [(4-cyanobiphenyl)-4'-yl]-heptane: A novel twistbend nematic? Phys Rev E. 2011;84:031704. DOI:10.1103/PhysRevE.84.031704.

[8] Luckhurst GR. Liquid crystal dimers and oligomers: experiment and theory. Macromol Symp. 1995;96:126. DOI:10.1002/masy.19950960103.

[9] Imrie CT, Henderson PA, Yeap GY. Liquid crystal oligomers: going beyond dimers. Liq Cryst. 2009;36:755777. DOI:10.1080/02678290903157455.

[10] Yeap GY, Osman F, Imrie CT. Non-symmetric chiral liquid crystal dimers. Preparation and characterisation of the (S)-(benzylidene-4-substitutedaniline)-2'-methylbutyl-4'-(4"'-phenyloxy)-benzoateoxy)hexanoates. J Mol Struct. 2016. DOI:10.1016/j.molstruc.2016.01.007.

[11] Lu Z, Henderson PA, Paterson BJA, et al. Liquid crystal dimers and the twist-bend nematic phase. The preparation and characterisation of the $\alpha, \omega$-bis(4-cyanobiphenyl-4'-yl) alkanedioates. Liq Cryst. 2014;41:471-483. DOI:10.1080/02678292.2014.888803.

[12] Gupta M, Pal SK. The first examples of room temperature liquid crystal dimers based on cholesterol and pentaalkynylbenzene. Liq Cryst. 2015;42:1250-1256. DOI:10.1080/02678292.2015.1036817.

[13] Kim YK, Breckon R, Chakraborty S, et al. Properties of the broad-range nematic phase of a laterally linked H-shaped liquid crystal dimer. Liq Cryst. 2014;41:13451355. DOI:10.1080/02678292.2014.920930.

[14] Seou CK, Ha ST, Win YF, et al. Synthesis and phase transition behaviours of new non-symmetric liquid crystal dimers. Liq Cryst. 2014;41:1627-1634. DOI:10.1080/02678292.2014.938373.

[15] Alshargabi A, Yeap GY, Mahmood WAK, et al. Nonsymmetrical liquid crystal dimers armed with azobenzene and 1,2,3-triazole-cholesterol. Liq Cryst. 2015;42:13371349. DOI:10.1080/02678292.2015.1052998.
[16] Hegguilustoy CM, Darda MB, Montani RS, et al. Symmetric bent-shaped liquid crystal dimers showing transitions between optically uniaxial and biaxial smectic phases. Liq Cryst. 2015;42:1013-1023. DOI:10.1080/ 02678292.2015.1013515.

[17] Imrie CT. Non symmetric liquid crystal dimers: how to make molecules intercalate. Liq Cryst. 2006;33:14491454. DOI:10.1080/02678290601140498.

[18] Yeap GY, Hng TC, Takeuchi D, et al. Non-symmetric liquid crystal dimers: high thermal stability in nematic phase enhanced by thiophene-2-carboxylate moiety. Mol Cryst Liq Cryst. 2009;506:134-149. DOI:10.1080/ 15421400902987248.

[19] Matharu AS, Cowling SJ, Wright G. Laterally fluorinated liquid crystals containing the 2,2'-bithiophene moiety. Liq Cryst. 2007;34:489-506. DOI:10.1080/ 02678290601176559.

[20] Butcher JL, Byron DJ, Matharu AS, et al. Properties of the liquid crystals formed by certain 4 '-n-alkylbiphenyl4-yl 5-n-alkylthiophene-2-carboxylates. Liq Cryst. 1995;19:387-396. DOI:10.1080/02678299508031996.

[21] Bunning JD, Butcher JL. X-ray diffraction studies of the liquid crystal phases formed by certain 4 '-n-alkylbiphenyl-4-yl 5-n-alkylthiophene-2-carboxylates. Liq Cryst. 1996;20:103-104. DOI:10.1080/02678299608032032.

[22] Yeap GY, Mohammad AT, Osman H. Synthesis, spectroscopic and mesomorphic studies on heterocyclic liquid crystals with 1,3-oxazepine-4,7-dione, 1,3-oxazepane-4,7-dione and 1,3-oxazepine-1,5-dione cores. J Mol Struct. 2010;982:38-44. DOI:10.1016/j. molstruc.2010.07.043.

[23] Yeap GY, Mohammad AT, Osman H. Synthesis and anisotropic properties of novel asymmetric diones fused with 1,3-oxazepine and oxazepane rings. Mol Cryst Liq Cryst. 2012;552:177-193. DOI:10.1080/ 15421406.2011.591687.

[24] Mohammad AT, Yeap GY, Osman H. Synthesis and mesomorphic behavior of new mesogenic compounds possessing a biphenyl ester moiety with a 6-amino-1,3dimethyluracil. Mol Cryst Liq Cryst. 2014;590:130-139. DOI:10.1080/15421406.2013.873857.

[25] Mohammad AT, Yeap GY, Osman H. Synthesis and phase transition studies of new dimer compounds connected to a 1,3-dimethylbarbituric acid core. Turk J Chem. 2014;38:443-453. DOI:10.3906/kim-1304-51.

[26] Hyperchem 8.0.8. Bruker program ID WIN-NMR (release 6.0) and 2D WIN-NMR (release 6.1). Bremen (Germany): Bruker Daltonik GMBH; 2010.

[27] Majumdar KC, Mondal S, Pal N, et al. Synthesis and mesomorphic behaviour of new mesogenic compounds possessing a cholesteryl ester moiety connected to a pyrimidine core. Tetrahedron Lett. 2009;50:1992-1995. DOI:10.1016/j.tetlet.2009.02.065.

[28] Mohammad AT, Yeap GY, Osman H. Synthesis, characterization and theoretical study of a new liquid crystal compound with an oxazepine core. J Mol Struct. 2015;1087:88-96. DOI:10.1016/j.molstruc.2015.01.043.

[29] Yeap GY, Hng TC, Yeap SY, et al. Why do non-symmetric dimers intercalate? The synthesis and characterisation of the $\alpha$-(4-benzylidene-substituted-aniline- $4^{\prime}$ oxy)- $\omega$-(2-methylbutyl-4'-(4"-phenyl)benzoateoxy) 
alkanes. Liq Cryst. 2009;36:1431-1441. DOI:10.1080/ 02678290903271504.

[30] Chan TN, Lu Z, Yam WS, et al. Non-symmetric liquid crystal dimers containing an isoflavone moiety. Liq Cryst. 2012;39:393-402. DOI:10.1080/02678292.2012.658712.

[31] Lee HC, Lu Z, Henderson PA, et al. Cholesteryl-based liquid crystal dimers containing a sulfur-sulfur link in the flexible spacer. Liq Cryst. 2012;39:259-268. DOI:10.1080/02678292.2011.641753.
[32] Donaldson T, Henderson PA, Achard MF, et al. Nonsymmetric chiral liquid crystal trimers. Liq Cryst. 2011;38:1331-1339. DOI:10.1080/02678292.2011. 613265.

[33] Date RW, Imrie CT, Luckhurst GR, et al. Smectogenic dimeric liquid crystals. The preparation and properties of the $a, \omega$-bis (4-n-alkylanilinebenzylidine-4'-oxy) alkanes. Liq Cryst. 1992;12:203-238. DOI:10.1080/ 02678299208030393. 